\title{
RETOS QUE PLANTEAN LAS NEUROCIENCIAS A LA ANTROPOLOGÍA FILOSÓFICA
}

\author{
ANTONIO SÁNCHEZ ORANTOS \\ Universidad Pontificia Comillas (Madrid).
}

\begin{abstract}
RESUMEN: Este artículo pretende ofrecer en diálogo con la Neurociencia un posible marco para definir críticamente el concepto de naturaleza humana y de persona. Intenta contribuir a afrontar el reto de los naturalismos en el pensamiento actual.
\end{abstract}

PALABRAS CLAVE: naturaleza humana, persona, neurociencia, emoción, sentimiento y memoria.

\section{Neuroscience challenges to philosophical anthropology}

ABSTRACT: This article aims to provide a possible framework to critically define the concept of human nature and person in dialogue with Neuroscience. He tries to help meet the challenge of the naturalism in the current thought.

KEY WORDS: human nature, person, neuroscience, emotion, feeling and memory

\section{INTRODUCCIÓN: UNA OPCIÓN METODOLÓGICA}

Vivimos tiempos difíciles para la reflexión antropológica y, por eso, como espero que quede mostrado implícitamente en estas páginas, para la propuesta ética. Esta dificultad no proviene exclusivamente de la ya aceptada crisis de la razón moderna, que se expresa a través de esos movimientos culturales que se presentan por el prefijo "post-»: postmodernidad, postmetafísico, postilustrado... En el seno de la Modernidad, a pesar de su subrayada pretensión de situar al yo humano como centro del pensar, y debido a la radical crítica realizada por la «nueva ciencia» sobre las "tradiciones de sentido», aparecen propuestas que ponen en entredicho las implicaciones que se derivan de la definición de "persona» e incluso la misma definición.

Realizar un recorrido de esta puesta en entredicho nos llevaría muy lejos y nos separaría de la pretensión de estas páginas ${ }^{1}$. Pero creo conveniente, a través de un sencillo esquema, recordar sus hitos fundamentales.

1) El mecanicismo fisicalista y sus conclusiones deterministas ponen en entredicho la posibilidad de la libertad humana y, por eso, la esencia misma de la definición de persona. Baste recordar la propuesta de Kant y su exigencia de que la reflexión filosófica responda a una única pregunta: ¿Qué es el hombre?

2) Determinismo que se encarna brillantemente en la propuesta anticartesiana de Spinoza donde sólo hay cabida para la natura naturans y la natura naturata.

3) Que crea un caldo de cultivo para el proceso de crítica de los llamados filósofos de la sospecha: Feuerbach, Nietzsche, Marx y Freud, que partiendo del naturalismo de Rousseau, culmina en su radical concepto de alienación humana.

1 Páginas que nacen de los fecundos diálogos tenidos por el Equipo de Investigación Naturaleza 2.0, dirigido por la Dra. Camino Cañón Loyes e inserto en los buenos trabajos de la Cátedra «Ciencia, Tecnología y Religión» de la Universidad Pontificia Comillas. 
4) Y que culmina, ya en las postrimerías de la modernidad, en el pensamiento anti-subjetivo de Heidegger, los existencialismos, estructuralismos y las posteriores secuelas postestructuralistas.

La atención crítica, sin prejuicios, a este proceso, y con independencia del valor de las propuestas de cada uno de los pensadores, mostraría ya la exigencia radical, urgente, de repensar la definición de lo humano. Pero además, a esta ya de por sí difícil problemática, se añaden en la actualidad los nuevos retos que presentan la Teoría sintética de la Evolución, las Nuevas Tecnologías de la Información y las denominadas sociedades científicas de Neurociencia.

Establecer con rigor un marco adecuado para enfrentar, evidentemente no para solucionar, la problemática insinuada, será el objetivo que estas páginas intentan cumplir. Y esta vez enfrentaremos el reto en diálogo con la Neurociencia ${ }^{2}$.

Pero antes de ofrecer dicho marco, conviene dejar clara la opción metodológica que guiará este caminar reflexivo:

1) Considero esencial para enfrentar la problemática señalada el diálogo interdisciplinar entre ciencia y filosofía/teología, evitando tanto los reduccionismos positivistas como los reduccionismos espiritualistas. Combatir la naturalización de la naturaleza humana no es un requerimiento espiritualista, sino exigencia máxima de verdad. Pero también, combatir la presunta inmunidad del discurso filosófico/teológico respecto a los datos de la ciencia, nunca podrá ser considerado sólo como un requerimiento positivista, sino también, exigencia máxima de verdad. Sólo así el diálogo interdisciplinar podrá ser fructífero. Sin olvidar que el filósofo/teólogo tendrá siempre la tentación de escuchar el discurso científico desde el prejuicio reduccionista positivista; y el científico de escuchar el discurso filosófico/teológico desde el prejuicio espiritualista. Entre estos extremos quiere mantenerse esta reflexión.

2) Y se trataría de buscar una posible marco que posibilite la (re)definición tanto del concepto de "naturaleza humana» como del concepto "persona», con el fin de (re)situar las aportaciones de la ciencia en un horizonte de eticidad que posibilite un verdadero sentido para la vida humana. Es decir, reconozco la existencia de condiciones naturales de lo humano: hominitas como condiciones sine qua non para caminar hacia la vida humana: humanitas ${ }^{3}$. Por tanto verdades de la ciencia abiertas a verdades de la subjetividad. Verdades de la subjetividad dialogando con las verdades ciencias. Lenguajes impersonales (tercera persona) y lenguajes personales (primera y segunda persona) buscando un sólido fundamento que permita su comunicación.

2 Para la problemática que presenta la Teoría sintética de la Evolución puede leerse: A. SÁNCHEZ Orantos (2010), "Las posibilidades del pensamiento de Darwin para pensar adecuadamente las "cosas" humanas» en González Garmendia, M. J. (coord.) (2010), Darwin, su tiempo y el nuestro. El paradigma evolucionista. Cátedra Pedro Poveda, Universidad Pontificia de Salamanca. pp. 45-68. Y para la que presenta las Nuevas tecnologías de la Información: Ortega de Mues, M., Sánchez Orantos, A. (2013), «Problemas que la reflexión filosófica tendría que enfrentar en el horizonte problemático abierto por las "nuevas tecnologías de la información” », Diálogo Filosófico, n 87, pp. 412-435.

3 Cf. Plessner (1981), Die Stufen des Organischen und der Mensch. Einführung in die philosophische Anthropologie, Gesammelte Schriften IV, Suhrkamp, Frankfurt, pp.64ss.; J. Moltmann (1976), El hombre, antropología cristiana en los conflictos del presente. Salamanca: Sígueme, pp. 19ss. 
En definitiva, se trata de asumir la tarea que Max Scheler propuso a la Antropología Filosófica en 1928, en su obra El puesto del hombre en el cosmos ${ }^{4}$ :

"Si se pregunta a un europeo culto qué entiende por la palabra "hombre", casi siempre empiezan a rivalizar en su mente tres círculos de ideas totalmente inconciliables entre sí. En primer lugar, el círculo de ideas de la tradición judeocristiana: Adán y Eva, la Creación, el Paraíso, la Caída. En segundo lugar, el círculo de ideas de la Antigüedad clásica, en la que la autoconciencia del hombre se elevó por vez primera a un concepto de su puesto singular en la tesis de que el hombre es hombre porque posee razón, lógos, phrónesis (sabiduría práctica), ratio, mens, donde lógos significa tanto lenguaje como capacidad de captar el "qué" de todas las cosas; estrechamente vinculada a esta intuición está la doctrina de que también a la totalidad del Universo le subyace una razón sobrehumana, de la que el hombre, y sólo él de entre todos los seres participa. El tercer círculo de ideas, que también se ha hecho tradicional hace ya mucho tiempo, es el de la moderna ciencia natural y de la psicología genética, según las cuales el hombre es un muy tardío producto de la evolución del planeta Tierra, un ser que sólo se diferenciaría de sus precursores en el reino animal por el grado de complejidad con que se combinan en él las energías y facultades, que en sí mismas ya están presentes en la naturaleza infrahumana. Estos tres círculos de ideas carecen de toda unidad entre sí. De este modo, tenemos una antropología científico-natural, otra filosófica y otra teológica indiferentes entre sí, pero no tenemos una idea unitaria del hombre» ${ }^{5}$.

\section{LA PROBLEMÁtica QUE DEBE SER ENFRENTADA}

Aunque los estudios del sistema nervioso tienen una larga historia, recordemos a Santiago Ramón y Cajal, recibieron un fuerte impulso a partir de los años setenta del siglo pasado con el surgimiento de las primeras sociedades científicas llamadas de Neurociencia, cuyo objetivo era enfocar el estudio del sistema nervioso desde perspectivas multidisciplinares. En paralelo, fueron surgiendo nuevas técnicas de estudio que han permitido expandir muy notablemente el conocimiento sobre el sistema nervioso. Entre estas técnicas debe destacarse el desarrollo, a partir de los años noventa del siglo pasado, de las técnicas de neuroimagen, que permiten el estudio del sistema nervioso humano vivo, una aproximación sin precedentes históricos, pues hasta entonces la investigación se limitaba a estudiar el cerebro humano post mortem y/o por analogía con cerebros animales. La década de los noventa fue la Década del Cerebro en los EEUU. En España, el año 2012 fue el Año de las Neurociencias.

Respecto a la filosofía, en 1986, Patricia Churchland publica Neurophilosophy. Toward a Unified Science of the Mind-Brain, que produjo una auténtica eclosión de nuevos saberes que se empezaron a denominar con el prefijo neuro-. A la neurofisiología se unen la neuroética, la neuroeconomía, la neuropolítica, el neuroderecho, la neuroreligión, la neurosociología, la neuroeducación... Valgan estas breves alusiones para subrayar la relevancia que estas investigaciones tienen en la cultura actual.

De manera general, el problema que debe enfrentarse puede enunciarse así: ¿podemos explicarnos a nosotros mismos? ¿No se cae en un círculo vicioso cuando se pretende conocer objetivamente la mente a través de la propia actividad mental? ¿Poseemos una facultad, la conciencia, con capacidad de aprehender el cerebro y la mente? ¿Hay

4 Scheler, M. (2000), El puesto del hombre en el cosmos. La idea de la paz perpetua y el pacifismo. Barcelona: Alba Editorial.

5 Ibid., p. 33. 
diferencia entre conciencia, mente y cerebro? Si esta diferencia puede sostenerse, ¿qué tipo de relación puede establecerse entre estos elementos? Subráyese lo que esta última pregunta supone: la mente, posibilidad de respuestas que procuran la viabilidad de la vida, sería una función del cerebro. ¿También la conciencia y la autoconciencia: "yo»?

Por tanto, aparecen tres conceptos que exigen definiciones precisas y una adecuada relación: cerebro (base fisiológica), mente (respuestas de la vida buscando su viabilidad: no necesariamente racional; y, por eso, el animal también sería inteligente), autoconciencia (distancia — juicio, valoración, finalidad...- respecto al cerebro y la mente).

\section{Posible(s) camino(s) de la Antropología Filosófica}

La antropología actual, el camino comienza en el s. XIX, ante los desafíos presentados, abandona progresivamente el concepto tradicional de la metafísica greco/cristiana: el alma espiritual inmortal, para definir la índole propia del ser humano. Su centro de atención será la corporeidad. La influencia de Nietzsche es masiva.

Esta ruptura ${ }^{6}$ con la tradición greco/cristiana se encarna fundamentalmente en dos grandes líneas de pensamiento:

1) La enraizada en el saber de la Psicología, de clara tradición empirista (Hume; Mill), que da lugar al conductismo.

2) La enraizada en el saber de la Biología, punto de partida de la antropología filosófica de Max Scheler, y entre cuyos cultivadores destacan Helmuth Plessner y Arnold Gehlen.

Ambas corrientes parten del supuesto anunciado: abandonan el recurso a la introspección y se centran en la conducta humana para intentar encontrar la índole propia de lo humano. Pero entonces, tienen que enfrentar con radicalidad crítica la propuesta que emerge de la psicología conductista.

El conductismo propone básicamente que la relación estímulo-respuesta (Pávlov) puede explicar todas las dimensiones del comportamiento humano. Evita, así, la noción de conciencia (interioridad), pero se obliga a asumir una postura negativa en la cuestión moderna del «puesto señero» del hombre en la naturaleza (Scheler). Y por eso, los límites del conductismo se convertirán, precisamente, en argumentos a favor de la búsqueda de la peculiar posición que le corresponde al ser humano en la naturaleza.

Si el conductismo hunde sus raíces en la tradición de la filosofía empirista, la respuesta crítica se radicará en la filosofía kantiana: las formas a priori del yo transcendental posibilitarán su actuar libre frente en el seno de la necesidad natural. Se trata de una defensa crítica y radical de la autonomía moral o voluntad racional.

\footnotetext{
6 ¿Ruptura con la tradición o modo diverso de interpretar los contenidos que la tradición ha ofrecido? La superación del dualismo cuerpo/alma, ¿implica, sin más, la negación de todo dualismo? ¿No se han propuesto nuevas hipótesis dualistas, por ejemplo, mente/cerebro? La tan acogida hipótesis emergentista, ¿no puede abrir tanto el monismo como el dualismo? Porque lo que está en juego, no debe olvidarse, es la búsqueda de una diferencia específica para lo humano. Sólo así podrá evitarse, exigencia máxima de verdad, la naturalización de la naturaleza humana. En definitiva, dos extremos: 1) ¿Puede ser reducido lo humano a su indudable origen natural? 2) Pero negar esta reducción, ¿puede suponer, sin más, que lo humano no tiene una estructura natural?
} 
Ahora bien, la propuesta kantiana tiene la posibilidad de ser interpretada biológicamente ${ }^{7}$. Kant no supuso que tanto las «formas a priori de la intuición» como las «categorías» pudiesen depender de la especificidad de los órganos del cuerpo. Y si éstos son productos de la evolución, es posible suponer que la experiencia de todos los seres vivos esté preformada por la configuración de sus órganos propios. La filosofía transcendental de Kant se transforma, así, en biología empírica: toda vida animal posee un esquema innato de comportamiento.

Obsérvese que aceptar esquemas innatos de comportamiento resuelve el problema fundamental que el conductismo presenta: cómo un mismo estímulo puede dar lugar, según especie y variaciones singulares, a reacciones diferentes. Las investigaciones de Piaget, la gramática generativa de Chomsky y las propuestas de Habermas y Apel acerca de la estructura de la competencia(s) comunicativa(s) asumirán este marco reflexivo.

Pero es Jacob v. Uexküll quien, siguiendo esta línea de pensamiento, propuso que todos los animales viven en su medio ambiente (entorno) de modo específico. La categoría de «entorno» no designará la inmensa variedad del medio ambiente en que vive el animal, sino el conjunto de notas a las que reacciona de acuerdo con su configuración específica: esquema innato de comportamiento (especie).

Pues bien, la antropología filosófica compartirá con el conductismo y la etología la necesidad de interpretar lo humano a partir de su corporeidad, es decir, a partir de su conducta observable. Pero supondrá que dicha conducta es un "comportarse», es decir, una exteriorización, precisamente, de esa interioridad caracterizada por poseer «esquemas» propios.

Y basándose en esta caracterización, encuentra un fundamento sólido para afirmar que el ser humano tiene un puesto señero en la realidad natural en cuanto su comportarse se define por su excentridad (Plessner) o apertura al mundo (Scheler; Gehlen). El comportamiento humano no estaría totalmente (esencialmente) determinado ni por los instintos, ni por la herencia genética, ni por las exigencias que impone el mundo circundante; sino por la consideración «real» de lo distinto de sí (Zubiri; Laín Entralgo), condición de posibilidad de la consideración «real» de su índole propia. Y el problema que debe ser enfrentado es si la ciencia neurológica confirma o no esta visión del ser humano.

En resumen, la antropología actual basa su comprensión de lo humano en la categoría de «apertura a la realidad», no reducible a la vinculación que la vida animal establece con su entorno. ¿Niega o confirma el saber neurológico este principio fundante de la antropología? Se trataría, pues, de enfrentar el alcance de las posibles explicaciones que la neurociencia ofrece de lo humano para descubrir si la antropología actual parte de un adecuado fundamento.

\section{NeURología y La ÍNDOLE PROPIA DE LOS HUMANO}

La Neurología, como saber científico, se presenta con un claro propósito: explicar objetivamente cómo se produce la denominada «conciencia subjetiva» (¿yo?) y si ésta puede críticamente mantenerse. Es decir, intenta una explicación científica del proceso de hominización (de la realidad física a la realidad vida y de ésta a la realidad humana) fundada en el método científico.

7 Cf. Lorenz, C. (1986), Fundamentos de la etología: estudio comparado de las conductas. Barcelona: Paidós Ibérica. 
El punto de partida es, pues, la aceptación, a grandes rasgos, de la teoría evolutiva en el marco que establece la teoría emergentista. Es decir, la vida humana procede de la vida, que a su vez debe ser explicada como una determinada configuración de los elementos de la realidad material (Oparin-Miller). La materia, de la que surgimos, nos configura, y, en interacción con ella, toda vida, también la vida humana, tiene viabilidad (conducta). Por eso, si queremos entender mínimamente el funcionamiento de la interioridad humana, el punto de partida debe ser, precisamente, la percepción sensible, es decir, la capacidad de aprehender el medio para hacer viable la vida: ¿Es la sensibilidad humana mera sensibilidad animal? Observemos que la respuesta afirmativa a esta pregunta obligaría a buscar una instancia distinta a la sensibilidad si quiere defenderse la índole propia de lo humano. ¿O es la sensibilidad humana diferente de la animal aunque (teoría evolutiva) debe reconocerse originándose en ella? ¿No debería distinguirse entre «origen» y "principio» para enfrentar críticamente los excesos de los evolucionismos? ¿Puede reducirse la novedad evolutiva a su «origen»? ¿Existiría entonces novedad? ¿En qué consiste esta novedad? ¿Cuál es su dinamismo? E inmediatamente puede vislumbrarse la aparición de: el soft-problem, el hard-problem y el really-hard-problem.

Antes de presentar dichos problemas, conviene precisar:

1) Que la única realidad a la que tengamos acceso directo sea nuestra experiencia consciente y, con ella, a nuestra existencia propia, no implica que sea la única dimensión que constituye lo humano. Porque a no ser que se admita que la subjetividad no tiene base material, es necesario afirmar que los hechos que la constituyen surgen de procesos físicos inconscientes (¿no debería repensarse la relación consciente/inconsciente sin obligarnos a los esquemas freudianos?). Si la base de estos procesos es el cerebro, entonces la pregunta se manifiesta con claridad: ¿Cómo el cerebro, realidad física, puede generar la realidad subjetiva? La convicción del saber actual es que la puerta de acceso a una posible respuesta es la investigación sobre la percepción sensible.

2) La subjetividad es un estado unificado. Integrada por muchos componentes (visuales, auditivos, olfativos, gustativos...), se nos presenta como un todo integrado (la impresión sensible es modal —el oído no sabe lo que el ojo ve; el tacto no sabe lo que el oído oye...-; la percepción es de un «todo»). Es decir, salvo en casos excepcionales, generalmente patológicos o provocados artificialmente, el ser humano nunca tiene la impresión de ser más de una conciencia al mismo tiempo. Subráyese lo que se afirma: la conciencia no remite solamente a la simple impresión sensorial.

3) La subjetividad se nos impone. Es decir, no poseemos ningún mecanismo para activarla o desactivarla voluntariamente, como hacemos, por ejemplo, con los ojos (abrir/cerrar). Y aunque es cierto que la atención está íntimamente relacionada con la conciencia subjetiva e influye en ella, deben ser claramente distinguidas: podemos ser conscientes sin prestar atención a nada particular (relajación; vacío meditativo...); podemos atender, estar pendientes de algo, sin necesidad de conciencia expresa (hábitos; la acción de conducir...) Pero además, la neurología nos enseña que la atención, en su tarea selectiva, dirige la información sensible hacia regiones corticales que procesan contenidos particulares; mientras que la conciencia subjetiva es el resultado de enviar el contenido de las impresiones a amplias regiones corticales, como se mostrará más adelante.

4) La conciencia, no debe olvidarse, nunca informa directamente sobre los mecanismos fisiológicos que acontecen en el cerebro: ocurren, repetimos, de forma inconsciente. Lo que la conciencia aporta es un resultado, el producto final de 
un procesamiento. El procesamiento de información en el cerebro precede a la propia conciencia, del mismo modo que la electricidad pasa por un cable antes de que se encienda la bombilla. Surge así un grave problema: ¿Está la conciencia totalmente determinada por procesos físicos? ¿Puede decidir contra ellos? ¿Puede moldearlos? ¿Puede dirigir sus respuestas según fines determinados por ella? ¿Cuál es el fundamento de la voluntad/libertad humana (voluntad racional)?

5) Es necesario no olvidar y pensar críticamente las condiciones de posibilidad de esa forma especial de conciencia que es la autoconciencia o metaconciencia (¿yo?). Ésta no aparece en ningún animal infrahumano. Algunos han afirmado que los chimpancés, los delfines e, incluso, los elefantes, tienen capacidad de autoconciencia, pero conviene advertir que todavía no ha podido demostrarse experimentalmente de manera convincente. Un aspecto crítico de la autoconciencia es el sentido de estar localizado en el propio cuerpo, en los límites de éste. Ahora sabemos que este sentido puede ser alterado, hay experimentos que lo confirman (drogas, convulsiones, apoplejías, instrumentos ópticos... que provocan que el individuo se perciba a distancia, más allá de su cuerpo); luego, debe reconocerse que la autoconciencia no es independiente de nuestras percepciones sensoriales, especialmente las somáticas.

6) La conciencia subjetiva dota a los seres humanos de una extraordinaria capacidad de interpretar el mundo y responder con gran riqueza de conductas (es la posible comparación/suficiencia-insuficiencia de la analogía con el robot) a las incertidumbres que las circunstancias imponen. Es la gran capacidad de adaptación del ser humano. Cada experiencia consciente tiene una determinada característica. A esos contenidos o cualidades subjetivas de cada una de las múltiples impresiones los llamamos qualia y su importancia reside en que integran una gran cantidad de información en una única percepción (pensemos en la percepción de una persona). Esa integración es muy útil para tomar decisiones sin tener que perder tiempo analizando con detalle cada una de las sensaciones que están a la base de toda percepción (crítica al psicologismo empirista). Gracias a la cantidad de información que nos proporcionan los qualia, el ser humano posee una extraordinaria flexibilidad en su comportamiento. ¿Cuál es la condición de posibilidad de los qualia? ¿El cerebro? ¿La mente? ¿La conciencia? ¿La autoconciencia? ${ }^{8}$

Y ahora estamos en condiciones de enfrentar los tres problemas insinuados más arriba.

\subsection{El soft-problem}

Se trata de si es posible remitir (¿reducir?) el fenómeno de la conciencia subjetiva a alguna actividad global cerebral o alguna estructura particular de éste, es decir, a determinados circuitos neuronales. Parece totalmente descartado que la conciencia pudiera radicar en un nivel subatómico, es decir, en las partículas que integran los átomos/ moléculas de las neuronas. En experimentos realizados llama sumamente la atención que la corteza prefrontal, la parte más evolucionada del cerebro, no parece necesaria para la conciencia. Individuos que han sufrido traumatismos o accidentes que han dañado dicha corteza, pueden seguir siendo conscientes aunque tengan alterada su capacidad

8 Cfr. para profundizar más en el tema: Morgado, I. (2012), Cómo percibimos el mundo. Una exploración de la mente y los sentidos. Barcelona: Ariel. 
de razonamiento. Es decir, no se puede identificar conciencia con razón. Se puede ser inteligente (respuesta adecuadas que posibilitan la viabilidad del ser vivo) sin necesidad de la lógica racional. ¿Obligaría esta constatación a revisar radicalmente la definición clásica del ser humano como animal racional?

El tálamo y sus proyecciones nerviosas bidireccionales con la corteza cerebral es la parte que no puede dañarse gravemente sin que se pierda la conciencia. Por eso, el tálamo ha sido denominado el umbral de la conciencia. Pero en situaciones de anestesia, se desactiva antes la corteza cerebral que el tálamo. Luego, el tálamo sería condición necesaria pero no suficiente para la conciencia. Por eso, se ha sugerido que la actividad consciente sería una actividad sostenida y recurrente desde áreas superiores a inferiores de procesamiento de información en la corteza cerebral, sin excluir, claro está, el propio tálamo. La conciencia sería el resultado de un bucle funcional entre la corteza cerebral y centros subcorticales.

Sin embargo, esta hipótesis, confirmada experimentalmente, no explica la unicidad que la conciencia implica (binding o ligamento perceptivo). Para explicar tal característica se han propuesto dos hipótesis: 1). Un lugar cerebral donde se integra toda la información recibida. Pero no se ha podido hallar tal lugar en el cerebro. Por eso, se propone que 2). La unidad perceptiva se logra no reuniendo, sino sincronizando con precisión la actividad de las neuronas de diferentes áreas de la corteza cerebral. La metáfora sería la orquesta sinfónica, diferentes instrumentos sonando de manera sincronizada. ¿Posibilitaría esta metáfora la necesidad de un director? ¿Qué o quién sería este director? Tononi, para evitar estas preguntas, ha propuesto otra metáfora: un poliedro cuyos diferentes lados representan los módulos funcionales, cada uno de ellos con cierta información consciente, que son integrados constituyendo la cara del poliedro. Esta segunda teoría es heurística en la medida que no sólo explica el carácter unificado de la percepción, sino también por qué la conciencia se nos presenta en grados diferentes en cada momento (cada una de las caras del poliedro). Y además, puede explicar el menor grado de conciencia que posee la vida animal, pues su cerebro, menos evolucionado, sólo permite integrar una limitada cantidad de información, muy inferior a la del cerebro humano.

\subsection{El hard-problem}

Para este problema la neurociencia no tiene respuestas tan claras. Se trata de explicar cómo tiene lugar el cambio cualitativo de la actividad física cerebral a qualia, es decir, cómo son posibles las diversas percepciones conscientes (ilusorias, reales: ¿creación?) que invaden nuestra mente. Y aquí es donde adquiere su fuerza tanto la imposibilidad de que la mente puede ser conocida por la propia mente, como las propuestas que la teoría evolutiva ofrece. ¿Hay una solución para el problema de la conciencia? ¿Es una limitación de la ciencia actual o la solución no es posible?

Una argumentación plausible para enfrentar estas preguntas sería la siguiente. Toda capacidad cognitiva del ser humano está, en principio, al servicio de la viabilidad de la vida en la circunstancia. ¿Qué aportaría a esta viabilidad el saber cómo se genera la conciencia? Utilicemos una analogía para una adecuada comprensión de la pregunta formulada: ¿qué aportaría a una comida sabrosa el saber cómo se engendra químicamente su buen sabor? Es decir, aunque pudiéramos concebir e incluso conocer alguna explicación convincente sobre cómo la fisiología inconsciente se convierte en psique consciente, y en qué consiste esta última, ese conocimiento sólo serviría para saciar nuestra curiosidad. Y la selección natural, que exige la viabilidad práctica de la vida, no proporciona respuestas a nuestras preguntas (aunque convenga preguntarse siempre 
por qué nos preguntamos), sino aquellas estructuras que son necesarias para la viabilidad de la vida. Si cambian las condiciones naturales exigiendo tal conocimiento, nuestra mente tendrá que evolucionar para llegar a respuestas adecuadas o no sobrevivirá. La neurología propondría un cierto escepticismo sobre las preguntas que la reflexión filosófica/teológica abre. Pero sin enfrentarlas, quizá la libertad humana quede sin fundamento, como trataremos inmediatamente. Porque queda un tercer problema: el really-hard-problem

\subsection{El really-hard-problem}

Aquí las respuestas son todavía menos claras. Se trata de responder al problema del origen de la autoconciencia o metaconciencia que supone, si se ha seguido adecuadamente el discurso, algo así como una «mirada no visible sobre lo invisible». Porque, ¿dónde está la subjetividad? ¿Cuál es su espacio/tiempo? ¿Quién mira y qué mira? ¿Cuál es el contenido de ese singular mirar? «Mirada no visible sobre lo invisible»: auto-presencia, auto-transparencia, en definitiva, autoafección, son ya características radicalmente opuestas a la materia y quizá no haya razones suficientes para no denominarlas con el término «espiritual» al querer resumirlas ${ }^{9}$. Pero además, es que esta autoconciencia es un «yo» que se apropia de todas las dimensiones descritas anteriormente sin identificarse con ninguna de ellas. Soy yo quien siente, imagina, fantasea y piensa, sin diluirme, manteniendo distancia, con lo que siento, imagino, fantaseo o pienso. Soy yo quien me siento diferente a mi cuerpo físico, como distinto de él. Y por este apoderamiento, el actuar yoico es radicalmente singular: no está esencialmente determinado por la materialidad. $\mathrm{El}$ «yo» al situarse más allá del espacio/tiempo poseería la posibilidad de desear y valorar más allá de cualquier realidad física, de cualquier esto o aquello; su deseo/valoración es autoelección, autodeterminación, posibilidad de configurarse electivamente; posibilidad, en definitiva, de libertad (voluntad racional). Desgajamiento del espacio/tiempo que determinan las realidades físicas, autonomía, vida en sí y para sí en lo otro de sí mismo.

Por todo ello, la antropología filosófica no ofrecería su contribución específica si se dejase reducir a los resultados alcanzados por la ciencia. El sujeto humano no es una cosa entre las cosas. Ninguna ciencia cosmológica, física, neurológica puede agotar su definición. Porque cuando hablamos de subjetividad, es decir, de percepciones sensoriales sentidas; de

\footnotetext{
9 La expresión really-hard-problem es empleada por el filósofo Chalmers en una célebre conferencia dada en 1994, con el título Toward a Scientific Basis for Consciousness (Journal of Conciousness Studies, vol. 2, no 3, 220-219). Sam Harris, en su libro El fin de la fe (p.214) plantea esta misma cuestión. Entre las afirmaciones que realiza en el capítulo titulado experimentos de la conciencia propone que en toda religión hay una firme convicción de que es propio de la condición humana la posibilidad de tener una experiencia radicalmente diferente del mundo. Explorar este terreno, verdadero logro del primate evolucionado, que incrementaría la felicidad de los seres humanos, dependerá de cómo se construya el discurso, precisamente, sobre iiila religión!!! A juicio de este autor, nuestras actuales creencias sobre Dios son el mayor obstáculo para un verdadero enfoque empírico de la experiencia mística; ya que «mientras que el misticismo es una empresa racional, la religión no lo es» (p. 225). Abolir las creencias sobre Dios dejaría libre el camino a esa empresa racional de reunir razón, espiritualidad y ética en nuestra forma de pensar el mundo. Y el hacerlo sería, a juicio de este autor, a la vez que el principio de un acercamiento racional a nuestras más profundas preocupaciones personales, el iiifin de la fe!!!. Es la naturalización de la espiritualidad. FLANNAGan (The really hard Problem: Meaning in a material World, MIT, Cambrige, Massachussets, 2007) y Compte-Sponville (La feliz desesperanza. El arco de Ulises. Barcelona: Paidós, 2001), se han expresado en términos muy parecidos. (Cfr. CAÑon LoYEs, C. (2014), El nuevo ateísmo científico. Estudios Eclesiásticos. Revista Teológica de Investigación e información. Vol. 89, n 349, pp. 307-336). Pues bien, la metáfora que hemos empleado: «Mirada no visible sobre lo invisible» pretende acentuar la imposibilidad del método científico para dar cuenta de esta posible «realidad» que definiría lo humano.
} 
imágenes representadas; de recuerdos vividos; de conceptos entendidos; de juicios, razonamientos y modelos teóricos concluyentes o no concluyentes; de discursos concatenando significados; de creencias convencidas; de preferencias, intereses, deseos, esperanzas vislumbradas; de temores sufridos... la referencia no puede ser solamente la realidad física externa, sino ese «mundo» propiedad exclusiva del yo. Es decir, el yo no sólo sería conciencia de algo diferente de él, como si fuese una «luz» siempre idéntica a sí misma que ilumina para ver lo diferente de sí; sino, ante todo, un «ser distinto» de sus contenidos conscientes, un «mundo propio» no derivable del «mundo ajeno», un estar entre las cosas sin ser cosa y sin ser solamente luz para que las cosas puedan ser adecuadamente vistas.

Porque lo que está en juego, como se anticipó más arriba, es el problema del fundamento de la libertad. La constatación de la anterioridad del proceso neuronal (inconsciente) respecto a la vivencia subjetiva, ¿bastaría para probar que los procesos cerebrales determinan todas las dimensiones de la vida humana? Si se respondiese afirmativamente, sin más, a esta pregunta, no cabría hablar de libertad o, como mucho, cabría hablar de ella como una ilusión: cuando creemos estar decidiendo, los procesos físicos cerebrales ya habrían decidido. Y recurrir a la física cuántica para defenderla no sólo es un mal recurso científico, fue insinuado más arriba, sino también filosófico, porque la indeterminación, el azar, no es, sin más, libertad. La libertad —es la propuesta de Kant- no puede reducirse a indeterminación: no tener razones para actuar es lo contrario a la libertad. La libertad es autodeterminación y los seres humanos no podemos actuar y, sobre todo, no podemos imputar responsabilidad a ninguno de nuestros actos sin presuponer su existencia. ¿Puede la explicación científica fundamentar la exigencia de libertad en la vida humana? ¿Puede existir, y si puede, pueden ofrecerse «pruebas» a favor de la libertad? Gazzaniga en el libro titulado el cerebro ético (Paidós, Barcelona, 2005) expresa con claridad el problema: «la neurociencia nunca encontrará el correlato de la responsabilidad, porque es algo que atribuimos a los humanos, no a los cerebros» (p. 111). Evidentemente, la libertad absoluta, totalmente desligada, no es libertad humana (recuérdese el «vuelo de la paloma» kantiano). Pero, ¿existe un espacio entre el orden natural y una posible libertad absoluta donde poder debatir y esclarecer el misterio de la libertad humana?

Quizá la reflexión sobre las emociones y, sobre todo, la reflexión acerca de esa maravillosa capacidad que es la memoria, posibilidad de biografía personal, arrojen luz sobre la pregunta formulada. ¿Puede fundamentarse la libertad en los procesos de inhibición del cerebro sobre las emociones? ¿Qué relación tendrían dichos procesos de inhibición con la memoria?

\section{NeUROLOGÍA Y COMPORTAMIENTO HUMANO: EMOCIÓN Y MEMORIA}

La emoción es, en principio, el conjunto de procesos fisiológicos involuntarios (sudoración, taquicardia...) que engendra el sistema nervioso central ante ciertos estímulos. Es decir, la índole propia de la emoción son los procesos fisiológicos desencadenados ante estímulos relevantes que preparan una respuesta para recuperar el equilibrio homeostático. El sistema simpático (excitación) y parasimpático (inhibición) serían la base física de estos procesos.

Pero, esta primera caracterización, fundamentalmente válida, no puede ofrecer una explicación completa de la experiencia emocional. Obliga a suponer que las respuestas fisiológicas son diferentes para cada uno de los estímulos emocionales. Si no fuese así, ¿cómo podría distinguirse la sorpresa de la tristeza, el miedo de la alegría...? 
En los años 30 del s. xx, Cannon y Bard, partiendo de estudios realizados sobre el sistema nervioso central, presentan su propuesta. Argumentaron que si las emociones fueran solamente aprehensión de cambios corporales tendrían que depender de la corteza motora/sensorial. Ahora bien, la eliminación de dicha corteza no suprime las emociones. En ausencia de corteza se produce, por ejemplo, la conducta de ira, aunque no esté acompañada por el sentimiento consciente correspondiente, porque, precisamente, las respuestas emocionales están controladas por el hipotálamo bajo la influencia de la amígdala. Es decir, la presencia de estímulo puede activar a la amígdala/hipotálamo directamente, sin pasar por la corteza sensorial. Concluyen que los sentimientos emocionales y las respuestas emocionales serían procesos paralelos en lugar de secuenciales.

Cuando acontece un estímulo, los impulsos nerviosos a través del tálamo llevan información a dos lugares del cerebro: a la amígdala/hipotálamo y a la corteza. El hipotálamo mandaría impulsos al sistema nervioso (cambios fisiológicos), acumulación de energía para la acción; y la traducción consciente (percepción) de dichos cambios, al ser enviados a la corteza (experiencia emocional), constituye el sentimiento. En definitiva, los cambios fisiológicos serían similares para distintos estímulos, variando la intensidad. En la corteza se percibe, desde estos cambios, la naturaleza del estímulo: si es una amenaza, algo inesperado, algo positivo... Esta percepción consciente (experiencia subjetiva de la emoción: valoración) es el sentimiento. La forma de interpretar las respuestas fisiológicas determinará, pues, la intensidad de las emociones (alta, media, baja intensidad); mientras que la forma de percibir cognitivamente las situaciones determinará la cualidad de la experiencia emocional (alegría, tristeza, miedo, sorpresa...).

Conclusión: Un sentimiento es una idea del cuerpo. El origen de los sentimientos está en el cuerpo, cuyos elementos están siendo cartografiados continuamente en la corteza cerebral. ¿El estímulo recorre sólo el circuito emocional? ¿Recorre el circuito de sentimientos? ¿Tiene que recorrer los dos? En definitiva, ¿el estímulo puede ser o sensorial/ mental o racional? ¿Hay estímulos racionales que pueden influenciar la conducta emocional?. Se trataría ahora de enfrentar, pues, el problema de la repuesta a la emoción/ sentimiento. ¿Colabora la razón (lóbulo frontal) en la respuesta emocional? ¿Se oponen razón y emoción? ¿Qué relación existe entre ellos? ¿Cómo se hace presente, si se hace presente, la emoción en el proceso racional? ¿Cómo se hace presente la razón, si se hace presente, en el proceso emocional? Antes de responder a estas preguntas, conviene establecer un adecuado marco de referencia

Primera referencia marco: la evolución es conservadora. Por eso, el cerebro humano es la unidad sistémica de «tres cerebros»

1) cerebro instintivo: región más primitiva del cerebro, constituida por el tallo encefálico, ubicado en la parte superior de la médula espinal, encargado de los instintos básicos de supervivencia: respiración, metabolismo de los órganos corporales, reacciones y movimientos automáticos. Asegura, pues, la supervivencia del individuo a través del deseo sexual, la búsqueda de alimento y las respuestas automáticas de pelea o huida. Base, por tanto, del comportamiento instintivo.

2) cerebro emocional: A partir del lóbulo olfatorio comenzó a cubrirse el tallo encefálico dando origen al diencéfalo, que comprende fundamentalmente el tálamo, hipotálamo, hipocampo y amígdala cerebral. Sede de las emociones, y al encontrarse ubicado debajo de la corteza cerebral permite una transmisión rápida de señales a la misma, con la consiguiente posibilidad de controlar nuestras emociones. 
3) cerebro racional: constituido por el neocórtex, ubicado por encima del sistema límbico, el cual, al haber evolucionado por medio del aprendizaje y la memoria, favoreció el desarrollo del lóbulo frontal (corteza prefrontal dorsolateral), sede de la inteligencia, el pensamiento, la imaginación, el símbolo, la creatividad.

Conclusión: el cerebro emocional y el cerebro racional no son, por tanto, independientes. No hay yuxtaposición de cerebros. Es un único sistema. No podemos encontrar en el cerebro una parte o puramente racional o puramente emocional. La corteza orbitofrontal y ventromedial y la corteza cingulada anterior hacen de puente entre emoción y razonamiento. La emoción determinando la razón, la razón determinando la emoción.

Segunda referencia marco: Lo afectivo es lo efectivo en la vida humana. Spinoza afirma: «...Cada cosa se esfuerza, cuanto está a su alcance, para preservarse en su ser...»; «...El empeño mediante el que cada cosa se esfuerza para preservar en su ser, no es otra cosa que la esencia real de la criatura.» (Ética, parte III, proposiciones 6, 7). Es el conatus, ímpetu por la autopreservación frente al peligro y las oportunidades. Acciones diversas de autopreservación que fundamentan la relación sistemática de las distintas partes y acciones de la corporeidad humana. Por eso, «una idea que excluya la existencia de nuestro cuerpo no puede darse en nuestra alma, sino que le es contraria» (Ibib., pr. 10). Y por eso también, «la fuerza de una pasión o afecto puede superar las demás acciones del hombre... Un afecto no puede ser reprimido sino por medio de otro afecto contrario, y más fuerte que el que ha de ser reprimido» (Parte IV, pr. VI-VII). Se trata, en definitiva, de reconocer que en la base de la acción humana están las emociones y los sentimientos.

Conclusión: lo afectivo es en principio efectivo en la vida humana. Las ideas, por sí solas, no transforman la vida humana. No por el hecho de pensar en la bondad, el ser humano es bueno. Ahora bien, ¿son las emociones y los sentimientos irracionales? ¿Qué ocurriría si se desconectara el cerebro emocional y el cerebro racional? ¿Quién mandaría en nuestro comportamiento? No se olvide que estamos buscando una posible relación entre mecanismos cerebrales inconscientes y autoconciencia.

La respuesta que debe darse a esta pregunta ha dejado de ser especulación teórica gracias a un acontecimiento casual ocurrido en Septiembre de 1848: el caso de Phineas Gage. Hombre maduro, equilibrado, racional, buen capataz en su trabajo. Una deflagración accidental de pólvora proyecta sobre su mejilla, a modo de lanza, la barra de hierro usada para compactarla y sale al exterior atravesando su lóbulo frontal. No murió. Ni si quiera perdió el conocimiento. Se recuperó poco a poco. Pero ya no era el mismo hombre. Se había producido una ruptura anatómica entre el cerebro emocional y el cerebro racional. Desde entonces sus respuestas emocionales dejaron de posibilitar la realidad de su vida, su viabilidad (inadaptación). Por tanto, cuando la razón no participa en la respuesta a la emoción, la respuesta emocional es incapaz de dar respuestas adaptativas. Ciertamente en la vida humana no se dará, salvo enfermedad o accidente, una ruptura anatómica entre el cerebro emocional y el cerebro racional. Pero sí pueden darse rupturas funcionales: pensemos en una situación de pánico provocada por el grito de fuego (sin que éste exista) en una sala de cine... La amígdala, memoria emocional, es conservadora, maneja mal la incertidumbre, busca respuestas rápidas de protección, sin que esto signifique que éstas sean siempre lo mejor: respuesta adaptativa. Aquí es donde se exige la intervención de la razón. Ahora bien, como la amígdala, que da órdenes al hipotálamo, está a la base de la acción humana, sólo si la razón es capaz de engendrar un estado emocional más fuerte que el provocado por el estímulo exterior, podrá guiar la respuesta emocional. Es la intuición de Spinoza: Un afecto no puede ser reprimido sino por otro afecto (lo afectivo es lo efectivo en la vida humana). 
La razón tiene que saber del estado emocional y, desde él, generar otro estado emocional que dirija la respuesta humana. Es la denominada moción interna o motivación, fundamento de la decisión humana. Y las preguntas filosóficas se disparan: ¿Cuál es la condición de posibilidad de estas mociones internas? ¿Son arbitrarias? ¿Desde qué criterios elabora la razón tales motivaciones? ¿Son criterios meramente culturales? Si así fuera, ¿podría darse la transformación de una cultura (revolución)? ¿Tienen su origen en la realidad externa? ¿Pertenecen a la realidad interna del ser humano (subjetividad)? ¿Puede un robot...?

Si se acepta lo argumentado, es necesario admitir que la «realidad de la vida», su viabilidad (adapatación), exige la «verdad de la vida», ser dirigida rectamente por la voluntad racional. La verdad de la vida no puede impedir su realidad; pero, la realidad de la vida exige saber de su verdad. Es la necesidad de una adecuada "ontología de la vida» como fundamento del actuar humano. ¿Cuál es su condición de posibilidad? ¿Dónde hunde sus raíces? ¿Cómo realizarla? Estos son los problemas que han sido señalados en el really hard-problem.

Pues bien, para responder adecuadamente a estas preguntas — como ya intuyó, en el horizonte de la filosofía griega, Platón; y, en el horizonte de la filosofía cristiana, San Agustín- es necesario enfrentar el problema de la memoria, porque es en ella donde quizá se acumulen esas creencias/valoraciones que pueden dirigir las respuestas humanas. ¿Qué dice la neurociencia sobre la memoria?

Todo aprendizaje supone la incorporación de datos novedosos. La memoria sería la capacidad de retener dichos datos: persistencia de lo aprendido. Pues bien, experimentos y reflexiones sobre diferentes patologías ${ }^{10}$ confirman que hay muchos tipos de memoria a las que corresponden distintos circuitos cerebrales.

1) Atendiendo al tiempo de persistencia de lo aprendido:

- Memoria a corto plazo, memoria primaria o working memory. Dura poco tiempo (segundos o minutos). Muy importante para la vida diaria: utilizada constantemente. Retiene información en el cerebro para ser utilizada inmediatamente.

- Memoria a largo plazo. Persistencia en el tiempo de lo aprendido.

10 El paciente H.M. fue operado en ambos hemisferios cerebrales para resolver sus ataques de epilepsias. Resección bilateral de la parte medial de los lóbulos temporales. Mejoró de sus crisis epilépticas y fue estudiado neurológicamente. Graves problemas de memoria. Incapaz de incorporar nuevos conocimientos y poderlos relatar. No perdió los conocimientos que ya tenía. Aprende habilidades motoras, pero no las recuerda después de terminarlas. Se le enseñó a leer en espejos; adquirió gran habilidad; pero no recordaba lo que había leído, es decir, no perdió la memoria de procedimientos (habilidades), sí la memoria declarativa: incapacidad de recordar lo aprendido y comunicarlo. Mantiene intactos los recuerdos de su infancia. La mayor parte de los recuerdos previos a su lesión recuperados como hechos, sin contenidos emocionales. Cuando se le hace el test de caras famosas sus respuestas son muy consistentes cuando se refiere a caras antes de su lesión. Después de la operación no recuerda caras. La lesión temporal no fue tan completa como se presumía. Una parte posterior del hipocampo se mantenía. Explica que su déficit de memoria no fuera total. Tenía conciencia de su problema. La idea que tiene de sí mismo es la anterior a la lesión. No tiene conciencia de sus cambios corporales. Mantiene una personalidad corporativa y educada. Del hipocampo depende la incorporación de nuevas memorias.

El Paciente R.B. sufrió un periodo de isquemia global en una operación de corazón. Amnesia anterógrada, incapacidad para incorporar nuevos recuerdos: daños en la memoria declarativa. La memoria remota se mantiene por encima de la media. Tiene una lesión en el lóbulo temporal que le impide incorporar memorias de tipo declarativo. Conclusión: el hipocampo está íntimamente relacionado con la amígdala: los contenidos emocionales refuerzan los contenidos de memoria.

Paciente N.A con lesiones en el tálamo, con apenas daño en el hipotálamo. Amnesia sobre contenidos verbales. 
2) Según las características de lo aprendido o formas de expresión:

- Memoria declarativa o explícita. Hace referencia a aquellos contenidos aprendidos que podemos expresar verbalmente. Contenidos, por tanto, que podemos recuperar porque son accesibles a la conciencia y pueden ser comunicados.

- Memoria semántica: afecta a hechos. Lo aprendido acerca de la realidad del mundo. Memoria compartida.

- Memoria episódica: momentos singulares que ha vivido el sujeto. Acontecimientos de la propia biografía. Memoria singular.

- Memoria no declarativa o implícita. Inconsciente. No podemos expresarla verbalmente, sí con movimientos corporales.

- Procedural memory: hábitos o habilidades motoras (uso de cuchillo y tenedor; montar en bicicleta). Memoria esencialmente motora que recuperamos haciendo los movimientos respectivos.

- Priming: efectos de huella de memoria en la posterior recuperación de determinados contenidos de memoria. Cuando somos expuestos a una determinada información, aunque no seamos capaces de recuperarla de manera consciente, mostramos que dicha información ha dejado una huella, porque somos capaces de responder de manera más acertada, al haber sido afectados por dicha información.

- Condicionamiento clásico: respuestas emocionales o esqueléticas cuando hemos sido expuestos a un determinado estímulo. Muy antigua filogenéticamente.

Pues bien, el almacenamiento de la memoria explícita no es estático. Los contenidos de memoria son plásticos, moldeables, en función de nuevos eventos (áreas corticales asociativas: almacenamiento de memoria) condición de posibilidad de su (re)interpretación. La memoria, por tanto:

1) Está a la base de la percepción: las sensaciones son fugaces y modales, necesitan ser retenidas para la constitución de objeto (percepción)

2) Es el fundamento del tiempo propio humano: El tiempo óntico es puro fluir. El tiempo humano (ontológico) es presencia en el presente del pasado (retención) y del futuro (pro-tensión: expectativa). La vida humana puede ser así proyecto.

3) Por eso, es el fundamento de la identidad personal: posibilidad de biografía propia. La memoria declarativa, distinta de la memoria implícita, no es un almacén de datos estáticos. Puede ser reinterpretada desde nuevas experiencias. Brevemente: libertad frente a los datos retenidos del pasado: posibilidad de interpretación (hermenéutica).

Y, por eso, la conclusión se impone. ¿No tendríamos que exigirnos una reflexión profunda sobre la memoria, revisando críticamente la propuesta platónica/agustiniana, para hacer luz sobre el fundamento de la verdad de la vida humana? ¿No sería central el tema de la memoria para intentar una definición de la naturaleza humana? ¿No es acaso la memoria el fundamento de la conducta humana, el sentido otorgable a las emociones: experiencias de pasado y expectativas de futuro mantenidas en el presente determinando las elecciones humanas? ¿Cuál sería la condición de posibilidad de esta determinación? 